\title{
Spatio-temporal analysis of Federal crop insurance cause of loss data: A roadmap for research and outreach efforts
}

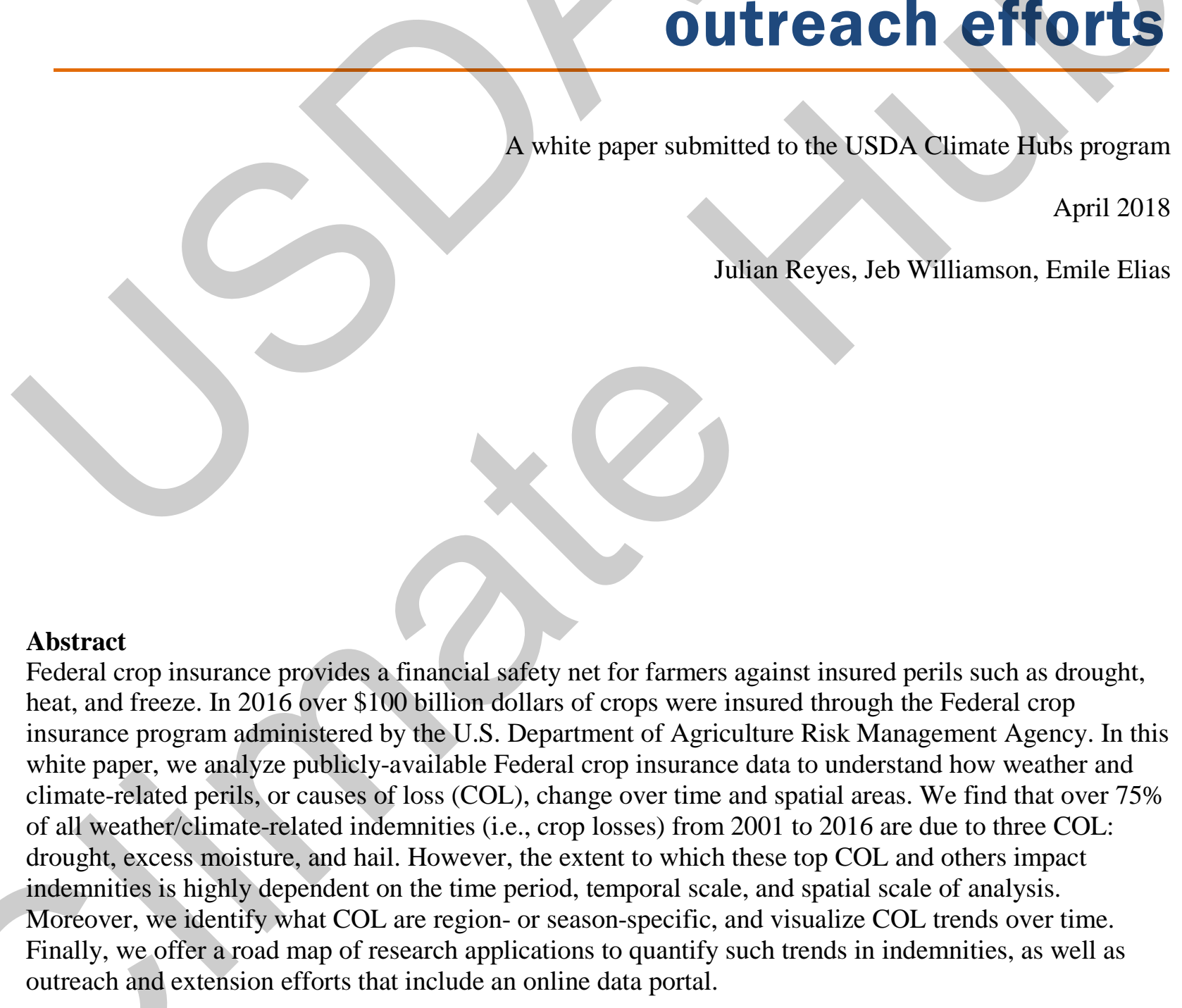

\section{Abstract}

Federal crop insurance provides a financial safety net for farmers against insured perils such as drought, insurance program administered by the U.S. Department of Agriculture Risk Management Agency. In this white paper, we analyze publicly-available Federal crop insurance data to understand how weather and of all weather/climate-related indemnities (i.e., crop losses) from 2001 to 2016 are due to three COL: drought, excess moisture, and hail. However, the extent to which these top COL and others impact indemnities is highly dependent on the time period, temporal scale, and spatial scale of analysis. Moreover, we identify what COL are region- or season-specific, and visualize COL trends over time. outreach and extension efforts that include an online data portal.
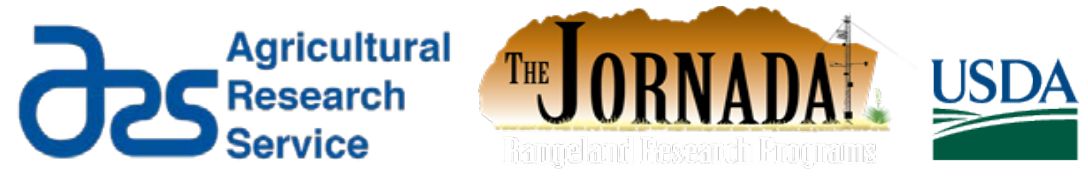


\section{Author Affiliations}

Julian Reyes, USDA Southwest Climate Hub/ARS Jornada Experimental Range, Las Cruces, NM Jeb Williamson, ARS Jornada Experimental Range.

Emile Elias, USDA Southwest Climate Hub/ARS Jornada Experimental Range, Las Cruces, NM

\section{Acknowledgements}

The authors would like to thank Andrew Eischens and Mark Shilts (USDA Risk Management Agency; USDA Climate Hub Liaisons) for their work as project Liaisons between the USDA Southwest Climate Hub and the Risk Management Agency. Mary Carey (USDA Farm Service Agency) and Sarah Wiener (USDA Southeast Climate Hub; U.S. Forest Service) for their insights and comments as reviewers for this document.

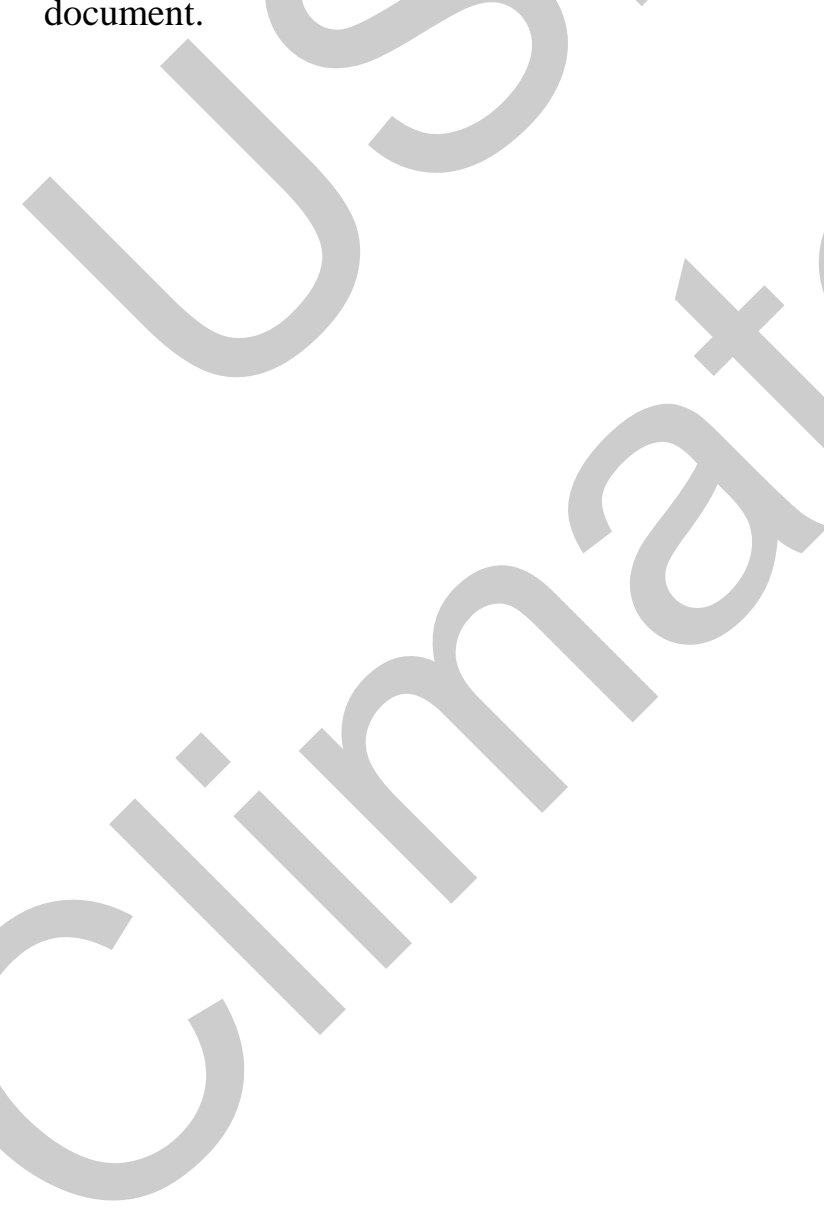




\section{$1 \quad$ Introduction}

Feeding nine billion people by 2050 amid increasing environmental and socio-economic pressures on our current agricultural production systems, is a serious challenge to meeting future food security (Godfray et al., 2010; Foley et al., 2011). Specifically, climate change impacts on United States agricultural production could decrease economic output by $\$ 50$ billion by 2080 (GAO, 2017). The highly complex interactions and dependencies between climate and agriculture have the potential to not only affect our food security, but also the livelihoods and communities that support such production (Hatfield et al., 2014). Given the significant impacts of extreme weather events and long-term climate change, Federal crop insurance serves as an important safety net for farmers (Shields, 2015).

In 2016, over $\$ 100$ billion of farmers’ agricultural commodities were insured through the Federal Crop Insurance Corporation (FCIC) managed by the U.S. Department of Agriculture (USDA) Risk Management Agency (RMA). RMA is responsible for administering and re-insuring the private entities that insure various crops (i.e., commodities) against natural perils and price declines (i.e., COL) (GAO, 2015; Shields, 2015). Federal crop insurance helps mitigate a producers' financial risk to weather and climate stressors, and helps minimize negative production impacts from insurable COL (e.g., drought, excess moisture, heat, hail, freeze, frost, etc.) (Smit and Skinner, 2002).

Federal crop insurance is viewed as a measure to provide adaptive capacity within the vulnerability framework, in which increasing climate variability may increase exposure to risk (McLeman and Smit, 2006). Data from these programs can also provide insight into additional adaptive measures. For example, vulnerability assessments often mention shifting crops to other regions in response to climate change (Walthall et al., 2012; Elias et al., 2016); however, changes in COL over time could provide an economic indication of which present crop-location combinations are becoming unsustainable. Past research has investigated whether patterns in crop losses over time are due to natural climate variability, anthropogenic climate change, or other drivers (Botzen et al., 2010; Bouwer, 2011; Bartel and Neumeyer, 2012). Therefore, loss trends in the Federal crop insurance program over time may tell us more about the sensitivity of a system to any of these future environmental changes, thus affecting the vulnerability of that crop/commodity and subsequent impacts on the communities dependent on the production.

\section{Objectives}

The objectives of our initial analysis are threefold: (1) understand how COL change over different spatial and temporal scales, (2) develop research questions related to trends in crop losses and those relationships with weather and climate, and (3) design media for sharing and disseminating these data and information to the general public. These objectives fit within the mission and scope of the USDA Climate Hubs program: develop and deliver science-based, region-specific resources and tools to enable climate-smart decision-making by farmers, ranchers, and forest land owners.

The long-term goal of this research is to support resilient working landscapes balancing the economic needs of livelihoods dependent on agro-ecosystems, but also future ecological viability and continued productive capacity. These findings will be shared with commodity groups and cooperative extension professionals across the nation to (1) better address climate risk related to agricultural production, (2) support future Federal crop insurance programs, and (3) move toward co-production of decision-relevant weather and climate information to stakeholders.

\section{$3 \quad$ Data}

We obtained COL data from historical data files publicly available through RMA (https://www.rma.usda.gov/data/cause.html). Data are available at the annual and monthly time step from 
1948-2016 and 1989-2016, respectively. Annual data were obtained from the "Indemnities only" COL historical data files, while monthly data were obtained from the "Summary of Business with Month of Loss" dataset. We analyze COL from 2001 to 2016 since acreage data are only available during this time period $^{1}$.

We use the R software and programming language to aggregate the annual and monthly files into singular datasets, respectively. Specifically, there are differences in the columnar layout of these files depending on the time period (i.e., 1989-2000, 2001-2010, and 2011-2016). Our first step involves integrating these different layouts and producing a dataset with consistent columns. The following elements are available in all three datasets: year, state code (FIPS), state abbreviation, county code, county name, RMA commodity/crop code, commodity/crop name, insurance plan code, insurance plan abbreviation, damage (i.e., COL) code, damage description (i.e., COL), and indemnity amount.

\section{Spatio-temporal analysis of COL}

\subsection{Overview}

We present initial analyses and on-going work related to our three objectives (Section 2). First, we show the top COL aggregated over time at different spatial scales, and then how COL have changed over time. Second, we provide possible research questions and methods for analyzing trends in COL via indemnities and correlations with weather and climate variables. Third, we demonstrate our outreach and extension activities to share Federal crop insurance data with diverse audiences.

\subsection{Spatial analysis of COL}

We aggregate weather and climate-related COL over differential spatial scales (i.e., national, regional, county-level) to assess how top COL may change as a function of the spatial unit of interest.

National scale. The top ten weather and climate-related COL are listed in Table 1 according to value of losses. These totaled \$104.69b and \$83.47b for the time periods 1948-2016 and 2001-2016, respectively. Regardless of the time period, drought and excess moisture comprise greater than two-thirds of aggregated indemnities. The top seven COL including drought have remained the top COL since 1948 over the Nation, and have also comprised almost $90 \%$ of nationwide indemnities. The last three top COL have changed over time with failure in irrigation supply and hot wind replacing frost and plant disease when comparing 2001-2016 to 1948-2016².

\footnotetext{
${ }^{1}$ However, this initial report does not present analyses with acreage information. Future research directions include using acreage to perform normalization on indemnities (see Section 6), as well as trend analyses on acreage affected by various COL. Moreover, acreage information is provided to the public via tools explained in Section 7.

${ }^{2}$ We note that differences in the top ten COL may also be due to reporting of eligible COL. According to publicly available data on the RMA website, hot wind first appears as a COL in 1982 and failure in irrigation supply (FIS) in 1983. In 1982, the COL categories almost double from 12 to 22 suggesting prior to 1982 these COL (i.e., hot wind and FIS) may have been lumped in another COL. This likely explains why there may be a shift in the top $10 \mathrm{COL}$ when comparing the two time periods. However, the comparison is still useful to examine the overall composition of COL for the Nation during these respective time periods. As noted, the rest of this analysis looks at COL 2001-2016 to account for such large changes in reporting, such as in the early 1980s.
} 
Table 1. Top 10 COL nationally from 1948-2016 and 2001-2016 sorted by indemnities by COL (billions of dollars).

\begin{tabular}{llll|lll}
\hline & $\mathbf{1 9 4 8 - 2 0 1 6}$ & & $\mathbf{2 0 0 1 - 2 0 1 6}$ & \\
\hline & $\begin{array}{l}\text { COL } \\
\text { indemnity }\end{array}$ & $\begin{array}{l}\text { Fraction } \\
\text { of total } \\
\text { indemnity }\end{array}$ & COL & $\begin{array}{l}\text { COL } \\
\text { indemnity }\end{array}$ & $\begin{array}{l}\text { Fraction } \\
\text { of total } \\
\text { indemnity }\end{array}$ & COL \\
\hline 1 & 47.80 & 0.43 & $\begin{array}{l}\text { Drought } \\
\text { Excess }\end{array}$ & 38.60 & 0.44 & $\begin{array}{l}\text { Drought } \\
\text { Excess }\end{array}$ \\
2 & 29.30 & 0.26 & Moisture/Precip/Rain & 23.50 & 0.27 & Moisture/Precip/Rain \\
3 & 8.85 & 0.08 & Hail & 6.55 & 0.07 & Hail \\
4 & 5.65 & 0.05 & Heat & 4.67 & 0.05 & Heat \\
5 & 3.87 & 0.03 & Freeze & 2.84 & 0.03 & Freeze \\
6 & 2.17 & 0.02 & Cold Wet Weather & 1.64 & 0.02 & Cold Wet Weather \\
7 & 2.15 & 0.02 & Wind/Excess Wind & 1.63 & 0.02 & Wind/Excess Wind \\
& & & Failure Irrigation \\
8 & 1.68 & 0.02 & Frost & 1.45 & 0.02 & Supply \\
9 & 1.66 & 0.01 & Flood & 1.34 & 0.02 & Hot Wind \\
10 & 1.56 & 0.01 & Plant Disease & 1.25 & 0.01 & Flood \\
\hline
\end{tabular}

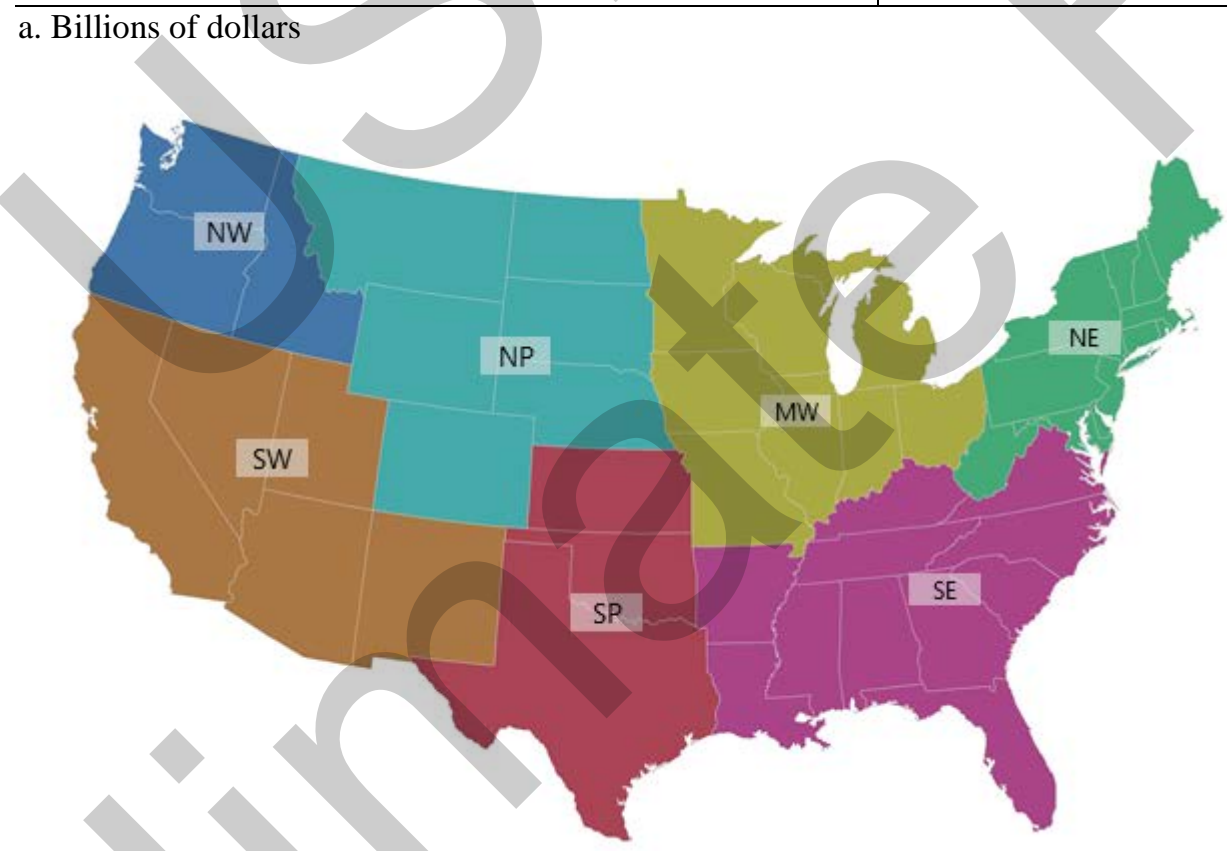

Figure 1. USDA Climate Hub regions for the conterminous United States. Seven regions are used in the regional-scale analysis of COL data: Northwest (NW), Southwest (SW), Northern Plains (NP), Southern Plains (SP), Midwest (MW), Southeast (SE), and Northeast (NE). While not shown, Alaska and Hawai'i are included in regional-scale analysis for the NW and SW regions, respectively.

Regional scale. We analyze COL at the regional scale aggregating data by USDA Climate Hub regions (Figure 1). The top ten national COL (Table 1; 2001-2016) are listed by region for 2001-2016 in Table 2. Figure 2 also shows these regional data in a visual format with the bubble size a function of the fraction of COL to total regional indemnities. The fraction of COL for nationwide indemnities is also included for comparison purposes (Figure 2). It is apparent that nationwide top COL differ by region indicating the diverse and interacting biophysical, climatic, socio-economic, and geo-political factors at play. These factors also affect what crops are grown in a specific area, which will also dictate what COL may be reported. 
Table 2. Top 10 COL by region as percent (\%) of total regional indemnities from 2001-2016. Shading indicates the first (red), second (blue), and third (green) largest COL by region. COL are ordered based on top 10 COL nationwide.

\begin{tabular}{llllllll}
\hline & MW & NE & NP & NW & SE & SP & SW \\
\hline Drought & 49.90 & 35.20 & 35.90 & 34.70 & 33.20 & 56.90 & 6.92 \\
Excess Moisture/Precip/Rain & 35.10 & 28.40 & 32.20 & 7.94 & 34.80 & 7.96 & 15.30 \\
Hail & 2.90 & 9.36 & 14.70 & 7.92 & 1.73 & 9.70 & 4.24 \\
Heat & 2.28 & 4.02 & 4.00 & 15.00 & 7.14 & 5.98 & 22.30 \\
Freeze & 1.02 & 7.59 & 1.48 & 8.15 & 4.05 & 5.61 & 9.59 \\
Cold Wet Weather & 2.33 & 3.37 & 2.30 & 4.88 & 0.74 & 0.43 & 5.39 \\
Wind/Excess Wind & 0.74 & 0.60 & 1.91 & 1.65 & 1.22 & 3.57 & 3.13 \\
Failure Irrigation Supply & 0.01 & 0.04 & 1.42 & 2.83 & 0.13 & 1.69 & 22.80 \\
Hot Wind & 0.08 & 0.04 & 0.83 & 0.41 & 0.04 & 5.26 & 1.55 \\
Flood & 2.80 & 0.60 & 0.49 & 0.12 & 2.28 & 0.37 & 0.12 \\
\hline Top 10 COL of regional total & $\mathbf{9 7 . 1 6}$ & $\mathbf{8 9 . 2 2}$ & $\mathbf{9 5 . 2 3}$ & $\mathbf{8 3 . 5 9}$ & $\mathbf{8 5 . 3 3}$ & $\mathbf{9 7 . 4 7}$ & $\mathbf{9 1 . 3 4}$ \\
\hline
\end{tabular}

While drought is the top COL nationwide, and in five of seven regions, it is only ranked $5^{\text {th }}$ in terms of total indemnities for the SW. Given the semi-arid to arid climate and on-going water issues, it is logical to assume drought as a major COL, as is the case with other regions. Instead, failure in irrigation supply (FIS), or lack of available water, is the top COL for the SW comprising almost a quarter of regional indemnities while FIS makes up only $2 \%$ of nationwide indemnities. This is unsurprising given the prevalence of irrigated crops in the region: more than $70 \%$ of crops in the SW are irrigated (Elias et al. 2015). Moreover, if those crops are insured under a FCIC irrigated policy and are affected by drought, FIS must be reported as the COL and not drought ${ }^{3}$. This is a stipulation of Federal crop insurance for those policies with an irrigated practice. While other perils like heat and hot wind normally do not occur under an irrigated practice, they may be appropriate COL given environmental conditions. Due to the policy stipulation on irrigated practices, we observe FIS as the leading COL in the SW rather than drought. However, it is important to note that drought is inextricably linked with the rise of FIS-related indemnities since by definition the former COL is defined as "lack of water." Furthermore, an irrigated practice might also reduce the impact of other COL like heat compared to a non-irrigated practice.

\footnotetext{
${ }^{3}$ https://www.rma.usda.gov/handbooks/25000/2017/17_25010.pdf Page 23, paragraph E.(1)\&(2)
} 


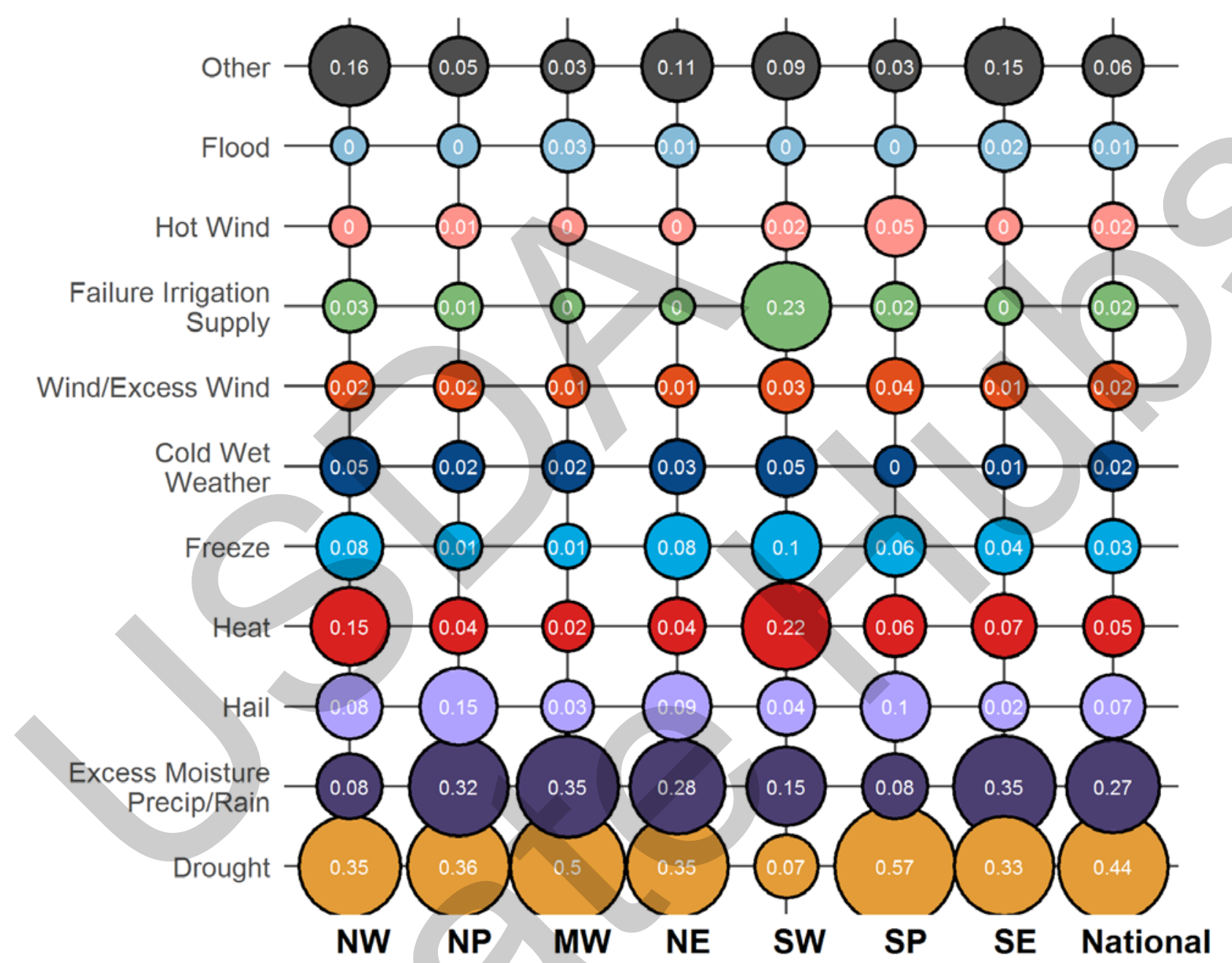

Figure 2. Relative fraction of aggregated indemnities from 2001-2016 for top 10 COL by Climate Hub region and across the Nation.

County-level. Over $88 \%$ of counties in the U.S. (2787 out of 3142) reported an indemnity from 2001 to 2016. Nationwide top 10 COL (Table 1) comprised the top county-level COL from 2001 to 2016 in 96\% of indemnity-reporting counties (2685 out of 2787). The frequency of these top COL by county are provided below in Figure 3. Almost half (49.8\%) of all counties in the U.S. reported drought as a top COL, and drought represents more than twice the number of counties for the next top COL, excess moisture. Interestingly, at the county-level the 'Other' category exceeds seven of the top 10 nationwide COL demonstrating the importance of local to regional-scale weather and climatic patterns, physical landscape characteristics (i.e., soil type, water availability), and socio-economic factors. In other words, spatial scale matters when examining COL as demonstrated in Figure 3. For example, hurricanes and tropical depressions as a COL will be significant in counties in the southeastern U.S. while frost may be more prevalent in other areas (keeping in mind these two COL are not in the top 10 nationwide COL, but are the top COL for certain counties). We show the top COL as reported at the county-level spatially in Figure 4. 


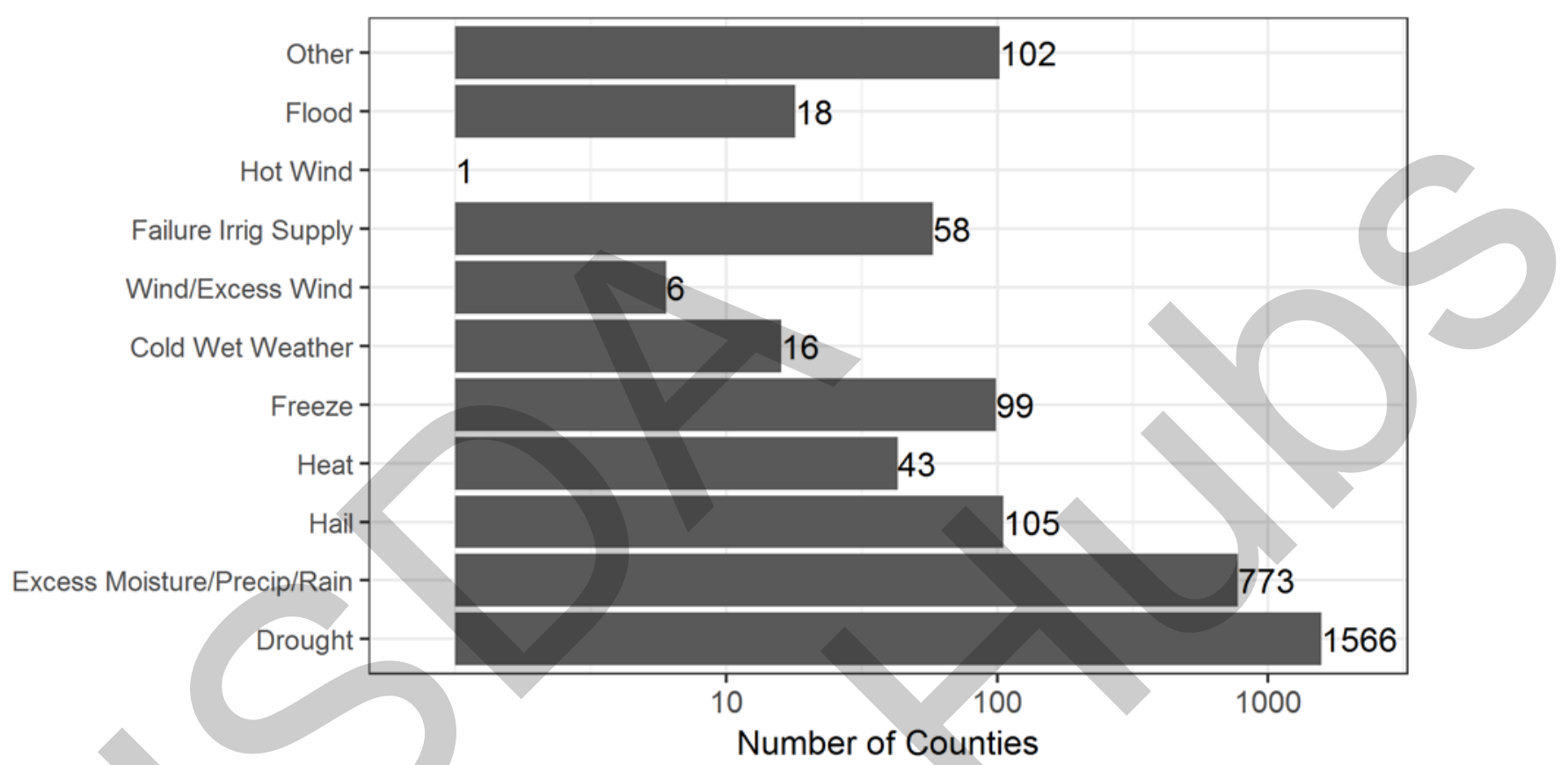

Figure 3. Histogram of counties by largest COL from 2001-2016. For example, drought comprised the largest fraction of aggregated indemnities for 1566 counties. In other words, 1566 counties have reported drought more often than other COL. Note that that the $\mathrm{x}$-axis is logarithmic.

Drought is a top COL by total nationwide indemnities and comprises a large swath of the conterminous United States (Figure 4). Essentially defined as a "lack of water," drought as a top COL over various spatial scales is no surprise given water's importance for crop growth and production. Impacts of drought on agricultural production and subsequent manifestation as a COL on an insurance crop are due to the simple fact that water is the primary controlling factor for crop production in a given location over time (Hatfield et al., 2011; Walthall et al., 2012; Hatfield et al., 2014). Increasing variability of seasonal precipitation affects soil water availability, which in turn affects plant water uptake and crop production. In addition, the large swath of the Great Plains and Midwest (i.e., corn belt) corresponds to areas where major crops are grown, such as wheat, corn, and soybeans, which also translates to high market value of agricultural products sold (Hatfield et al., 2014). Moreover, drought can operate on multiple time scales with increasing severity as precipitation levels remain below average causing decreasing soil water availability. As mentioned, this will slowly decrease plant water availability. It is no surprise to see drought as a top COL in much of the conterminous U.S. since lack of water diminishes a fundamental resource for crops. Also, extended drought periods can have carry-over effects into subsequent years also affecting crop production.

We also note that drought is often associated with warmer temperatures. During these times, extreme heat events may also increase crop damage. As discussed above, drought and heat may also result in less available water for irrigated crops, such as those in the SW. Many of the counties that report FIS as a top COL are located in semi-arid to arid environments of the Western U.S. (e.g., eastern Oregon, southern Arizona, and southern New Mexico).

As mentioned, the top 10 nationwide COL are used to characterize the top county COL; however, these nationwide COL may not be representative of local landscape and socio-economic conditions and/or climatic regimes. For example, Florida features 58 counties showing “Other” as a top COL (2001-2016; Figure 4). These top COL include Asiatic Citrus Canker, frost, hurricane/tropical depression, plant disease, and storm surge. The prevalence of citrus crops in this mild climate, as well as increased 
susceptibility of impacts from tropical weather systems explains these "Other” top COL for Florida. Counties in the Pacific Northwest (i.e., Washington, Oregon, and Idaho) primarily report frost as their top COL. The high fraction of indemnities not in the top 10 nationwide COL (i.e., reported as other) in certain areas demonstrates the importance of spatial scale in COL analysis, as well as the high geographic variation in both COL and crops across the U.S.

County-level COL data characterize both the homogeneous and heterogeneous nature of agricultural production due to multiple interacting factors: biophysical (i.e., climate, soils, resource availability), management (i.e., fertilizer management, crop selection, previous agricultural production), and socioeconomic (i.e., local or state policies, employment conditions, livelihood, cultural, etc.).

Our results indicate that areas with more homogenous COL (Figure 4) - as a fraction of total indemnities (aggregated and/or annual) - may have less crop diversification. Producers are likely limited by biophysical conditions like climate that restrict growing degree days for multiple crops. For example, citrus and cotton crops are not grown in the northern tier of the country because of the temperature requirements of these crops. Moreover, annual crops dominate the northern tier of the country which may hinder the ability to diversify. However, homogeneity in COL may also tell us about management and socio-economic conditions. Farming operations can potentially reduce fixed costs (i.e., inputs, equipment) with homogeneity in crop selection. A specific example is the state of Kansas where there is homogeneity in both crop (i.e., wheat) and COL (i.e., drought). Homogeneity in crops may be an inherent risk as compared to crop diversification as a risk management strategy. Regions with a larger mix of top COL, or heterogeneity in perils, may imply crop diversification, which may also lessen the impact of any single

COL. With crop diversity, there is greater variation in planting dates, harvest dates, growing season length, water requirements, and management.

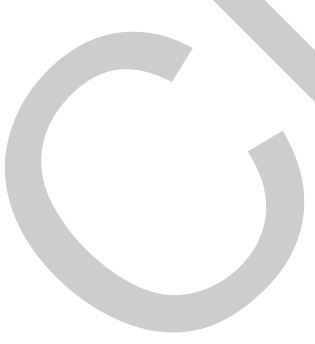




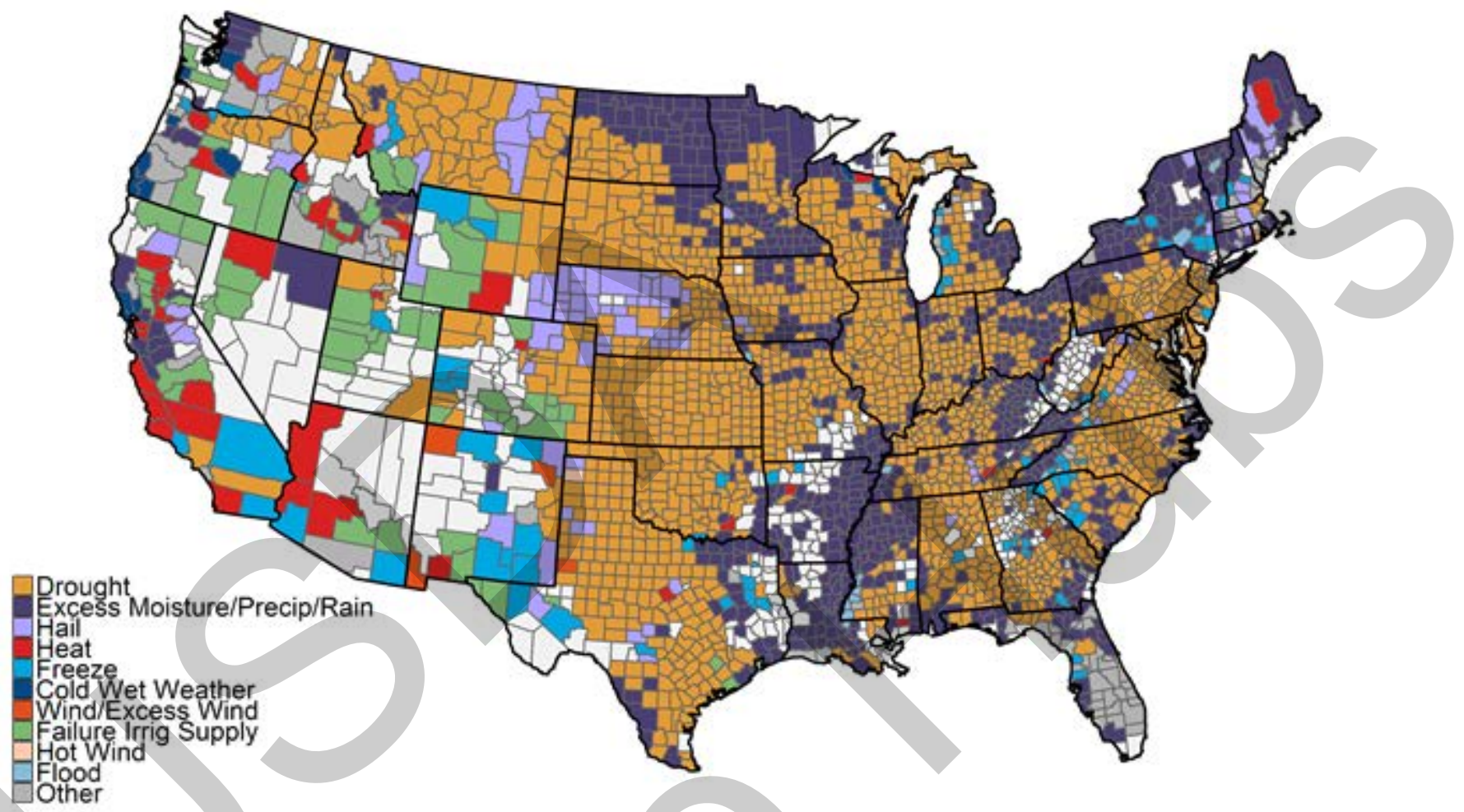

Figure 4. Top COL by county for aggregated indemnities (2001-2016) for the conterminous United States. White-shaded counties indicate no climate-related COL reported for this time period. Gray-shaded counties (e.g., in Massachusetts and Florida) indicate top COL not listed in the nationwide top ten COL.

\subsection{Temporal analysis of COL}

Annual indemnities. Annual indemnities from 2001 to 2016 are shown by COL in Figures 6 and 7. In general, annual indemnities increased significantly during drought events between 2011 and 2014.

Especially in 2011 and 2012, indemnities related to heat as a COL increased simultaneously along with drought. However, heat (red), failure in irrigation supply (light green), and hot wind (light pink) also increase in absolute indemnities during this time. Drought and excess moisture make up the largest absolute value of annual indemnities over time. In cases where drought-related indemnities comprise the $2^{\text {nd }}$ largest portion of total annual indemnities, excess moisture is responsible for the largest portion of annual indemnities (e.g., 2009, 2010, 2014, 2015, 2016). 


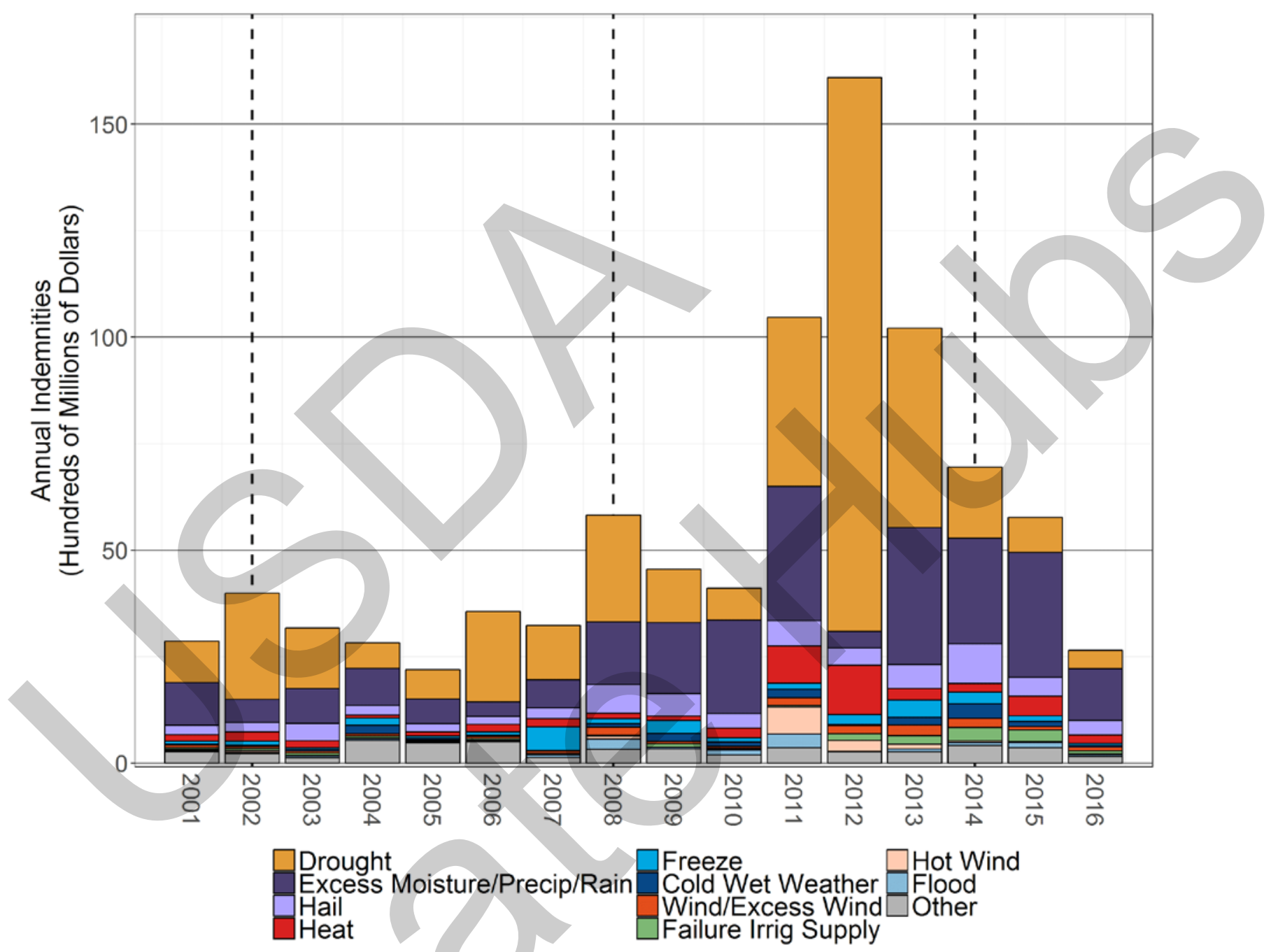

Figure 5. Bar plot of absolute annual indemnities (hundreds of millions of dollars) for climate-related COL from 2001 to 2016. Dashed lines indicate passage of the Farm Bill. 


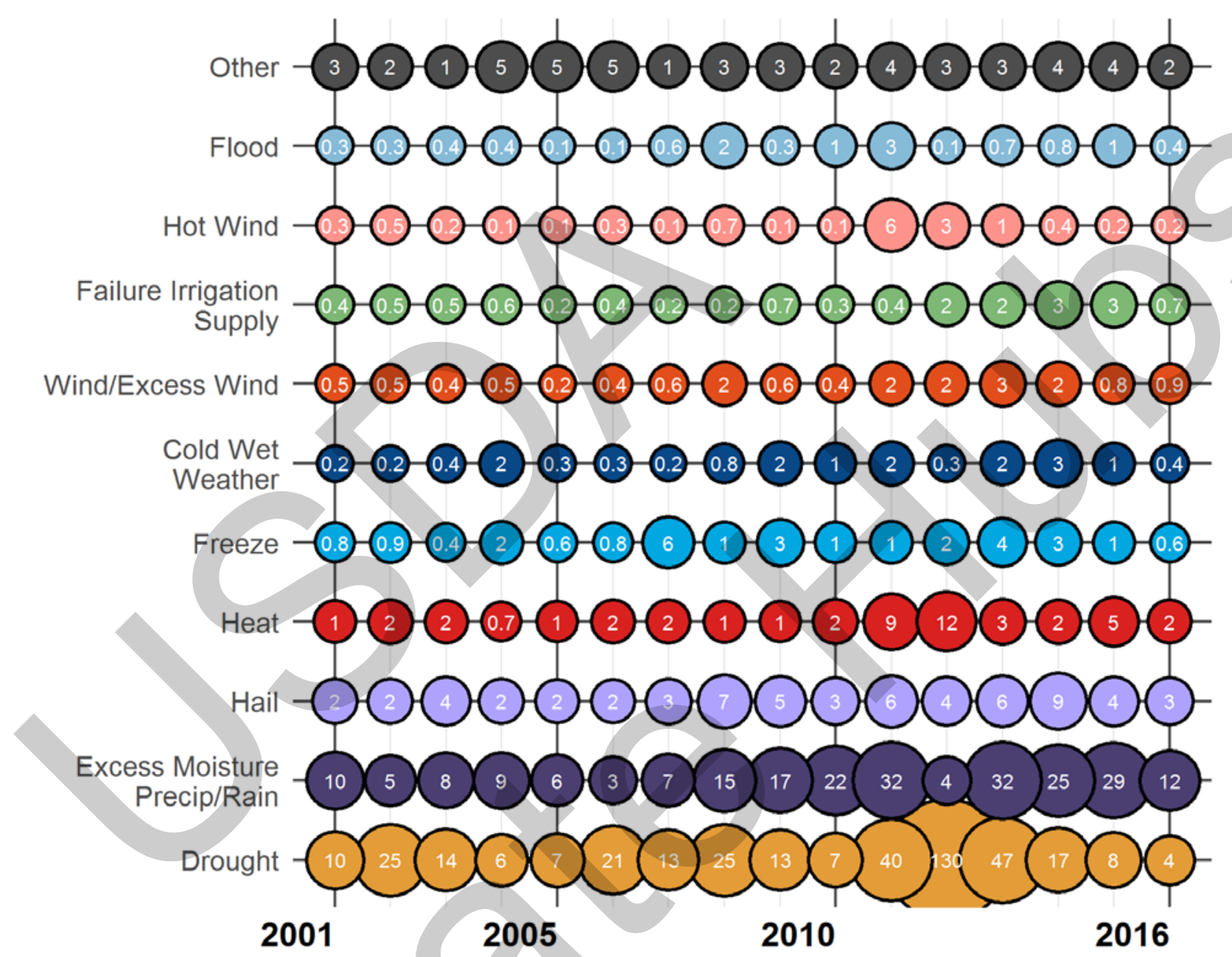

Figure 6. Bubble plot of absolute annual indemnities (hundreds of millions of dollars) for climate-related COL from 2001 to 2016. Size of circle indicates amount of annual indemnity.

Similar to Figure 5 showing absolute indemnities by COL over time, we also show the fraction of annual indemnities by COL (Figure 7). We observe that drought and excess moisture comprise more than half of annual indemnities for the time period of analysis (2001-2016). In some cases, these two COL account for over 75\% of indemnities, such as 2002 and 2013. We note that the relative proportion of annual indemnities by other COL such as hail (light purple), heat (red), freeze (light blue), and hot wind (pink) is easier to distinguish as compared to analyzing their absolute indemnities. We also note the increasing prevalence of FIS (light green) after the major drought of 2012, and simultaneously occurring with larger relative indemnities related to heat (i.e., 2014-2016). 


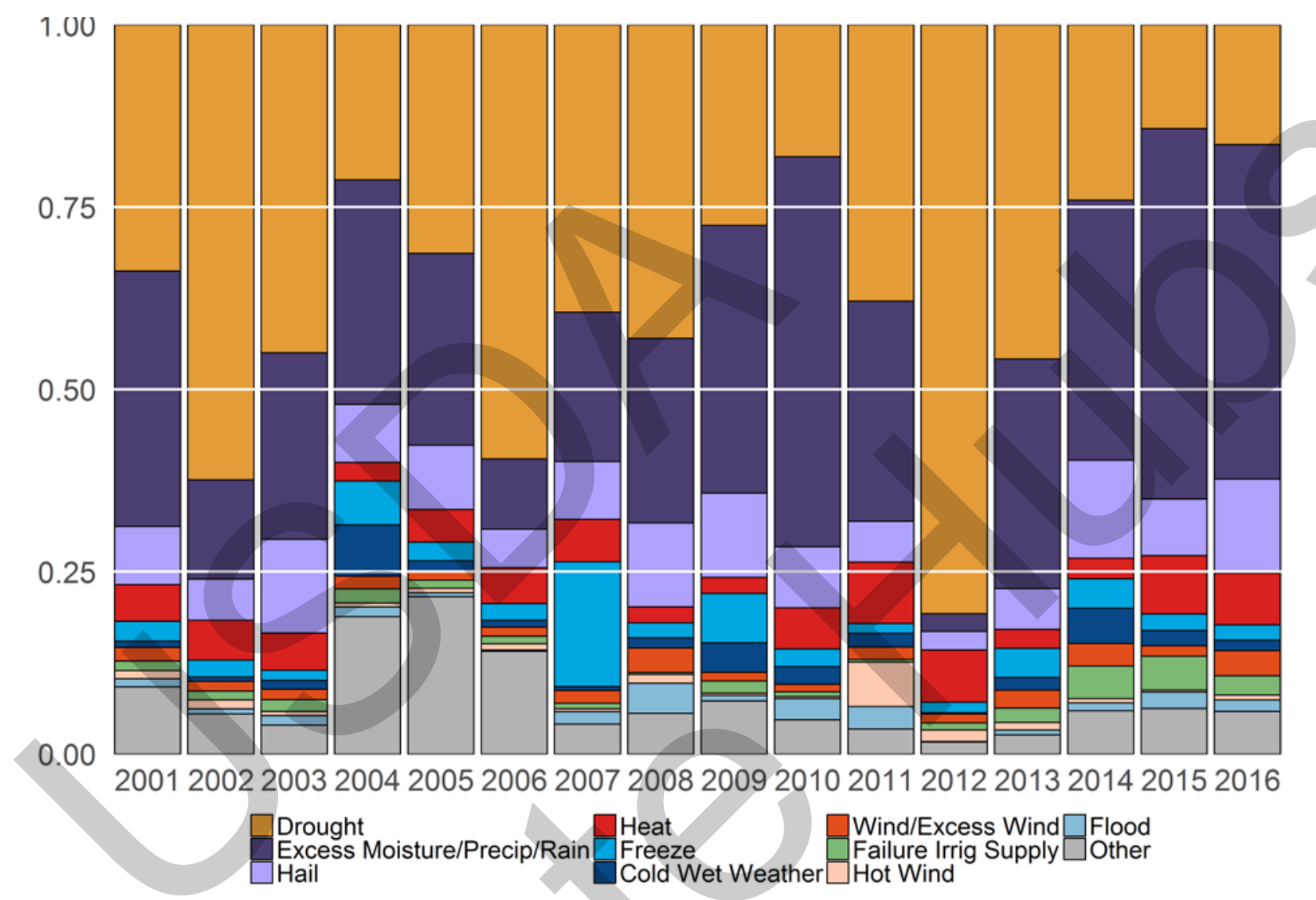

Figure 7. Fraction of annual indemnities (i.e., relative indemnities) by climate-related COL from 2001 to 2016.

Annual indemnities by grouped COL.

We group COL into categories of “Cold/Frost/Freeze”, "Hot/Dry”, and "Other” to better understand any patterns among them over time. COL have been categorized in the following manner: cold/frost/freeze (i.e., cold winter, cold wet weather, frost, freeze), hot/dry (i.e., drought, heat, failure in irrigation supply, insufficient chilling hours, hot wind), excess moisture/hail (i.e., excess moisture/precipitation/rain, hail), and other (i.e., flood, wind, etc.). We initially examined grouped COL without explicitly representing excess moisture and hail, and found a strong negative correlation with hot/dry and other categories which we attributed to excess moisture and hail COL. Therefore, we pulled out excess moisture and hail due the relationship with hot/dry COL, and their importance as a nationwide COL (Table 1).

As shown in Figure 8, there is a negative correlation between the hot/dry (dark yellow) and excess moisture/hail (purple) COL categories. While we do not quantify the correlation coefficients in this study, one can see the general relationship between the two COL: as relative indemnities related to hot/dry COL increase, relative indemnities related to excess moisture/hail decreases. This negative correlation is not unexpected as in years where cooler and wetter conditions are prevalent, a drop in hot/dry COL is to be expected. However, the negative correlation is surprising at the national scale given local to regional differences in COL and crops grown. We note that fraction of annual indemnities is determined from total amounts in Figure 5; however, we now group certain COL and calculate a separate relative annual indemnity. 
Interestingly, with the exception of a few individual years, overall there does not appear to be a correlation between the hot/dry and cold COL categories. The lack of correlation is likely due to the localized nature of individual frost and freeze events, as well as the differences in season in which these COL occur (i.e., cold/dry more likely in winter versus hot/dry in the summer). However, there are also long-term differences in these categorical COL as drought may occur in any season and have multi-year impacts. For example, it is possible to have a cold spring and dry summer, or wet summer and early fall frost within the same growing season. Moreover, the lack of correlation between cold/frost/freeze and hot/dry brings to focus that moisture, or lack thereof, is an important COL alongside hotter/drier and cooler conditions. Not only do we see this through the fraction of annual indemnity by various COL categories over time, but previous assessments of weather and climate on agriculture also affirm precipitation and soil moisture as controlling factors on crop growth.

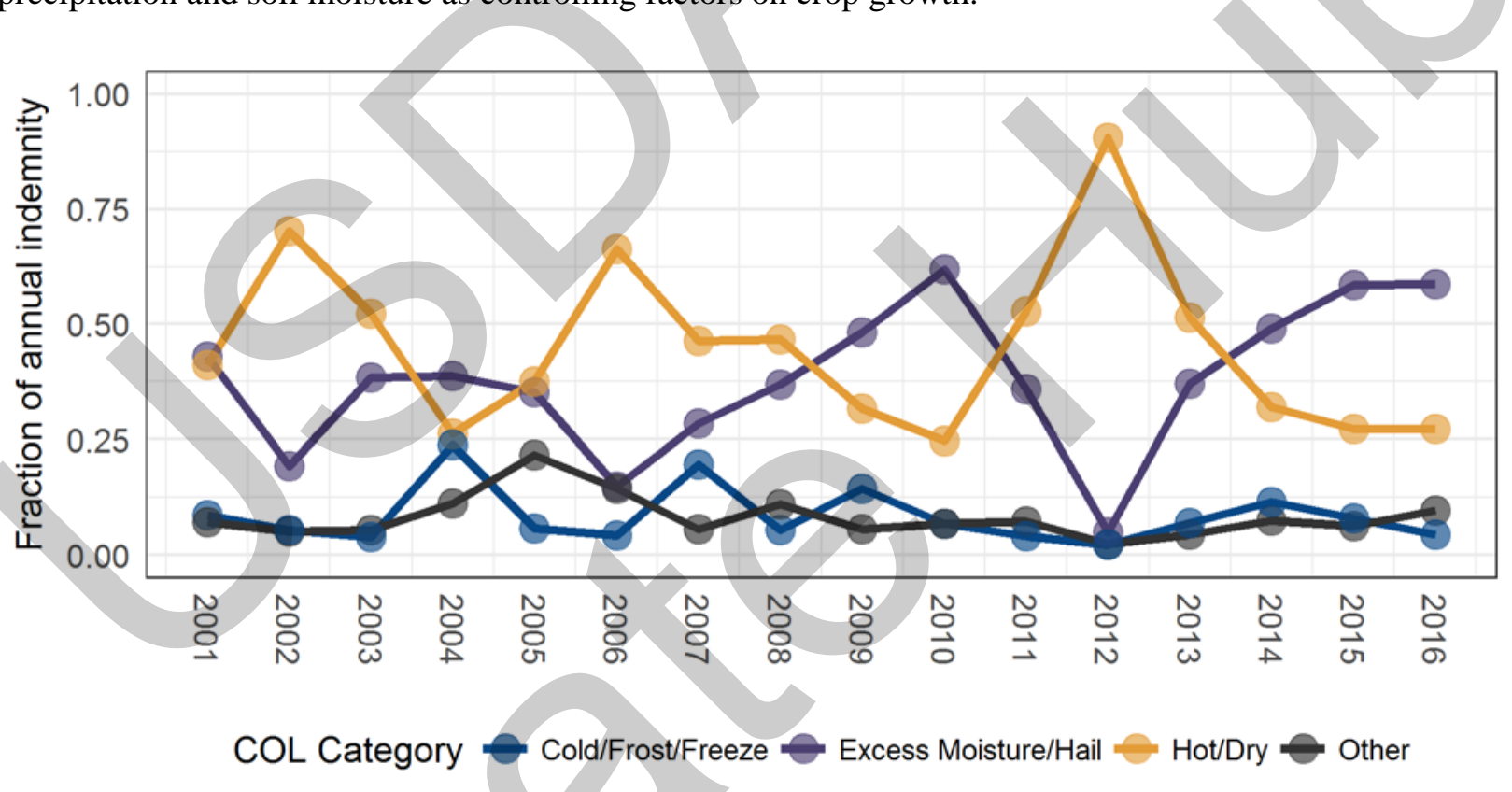

Figure 8. Fraction of annual indemnity by selected COL categories.

\subsection{Spatio-temporal analysis of COL}

Regional indemnities by COL over time. We extract nationwide indemnities by COL and USDA Climate Hub region at an annual time step to examine the effects of both space and time (Figure 9). While drought and excess moisture/precipitation/rain make up the majority of most annual COL, some regions show other COL comprise the majority of annual indemnities. For example, the NW features heat, freeze, cold wet weather, and other as COL that make up more than half of annual indemnities in most years. In the SW, failure in irrigation supply and heat make up at $25-50 \%$ of annual indemnities. Many of the nationwide top 10 COL are not top COL in the SE as evidenced by the high fraction of other COL, especially from 2004 to 2006. These COL are most likely attributed to crop damage from hurricanes and tropical depressions. Wind/excess wind and hot wind appear distinctly for the SW and SP, which may be indicative of the climatic regimes there but also crops that may be more sensitive to those COL. Hail appears as a large relative fraction of total annual indemnities for NW, NP, and SP. 


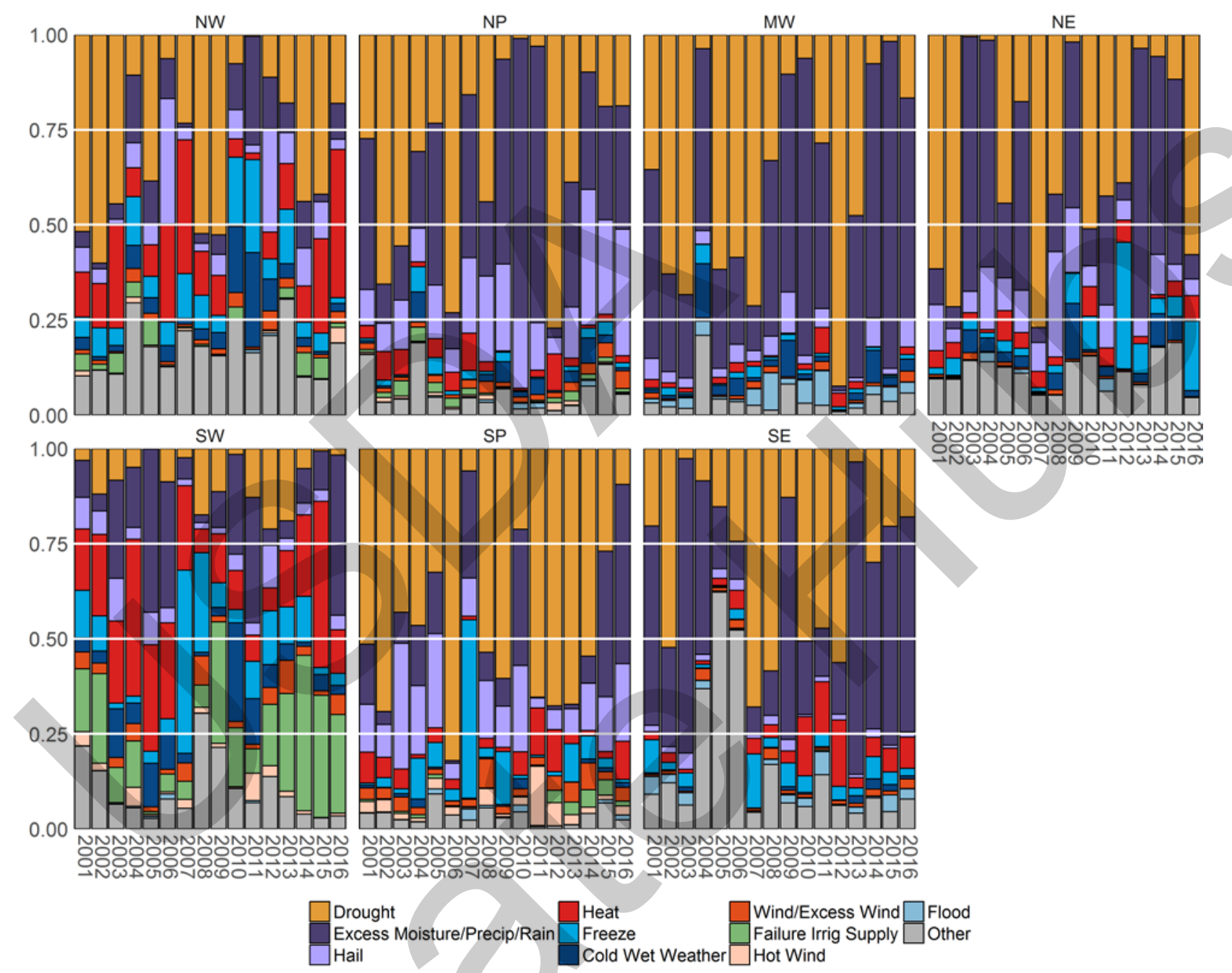

Figure 9. Fraction of annual indemnities by COL by USDA Climate Hub Region from 2001 to 2016.

Regional indemnities by month and COL over time. We can further divide regional annual indemnities by COL and month (Figure 10). Each row represents a calendar month starting with January at the top to December at the bottom, while each column is a Climate Hub region. In general, annual patterns of COL (Figure 9) are not indicative of monthly patterns since different COL occur at different times of the year. However, we may also observe impacts from longer-term climatic events such as drought. Moreover, fraction of monthly indemnities by COL over time shows us how these perils have changed or shifted both intra- and inter-annually (i.e., within season and by season over time).

Drought (orange) has been reported as a COL in almost all months (from 2001 to 2016) in all regions. This COL plays a large role in the MW and SP regions where drought can comprise greater than $75 \%$ of monthly indemnities. While drought is commonplace as a COL in the SP throughout the year and during the period of analysis, the 2011-2013 drought is noticeable especially in the winter months as drought comprises greater than $50 \%$ of monthly indemnities. In other regions, drought is more prevalent in particular seasons, such as summer months for the SE and summer to early winter for the MW. There also seems to be a negative correlation between drought and the excess moisture/hail (purple and light purple) COL. In regions and years where drought comprises a large portion of monthly indemnities, there are fewer instances of excess moisture and hail as COL. The opposite is true and exemplified during late spring and summer for the NP, MW, and NE where this interplay between these COL is most noticeable. 
COL related to excess moisture (dark purple) have been consistently reported during spring and early summer months in the MW from 2001 to 2016. Since 2012 excess moisture has also increased its proportion of monthly indemnities from July to December for the MW, and in most cases exceeds $50 \%$ of monthly indemnities as a COL. Other regions also feature large relative proportions of monthly indemnities due to excess moisture such as the NP, NE, and SE regions, albeit at different times of the year. Since 2013, the SE has seen a large dominance of excess moisture as a COL from January to May, and October to December.

Compared with other top 10 COL, occurrences of hail (light purple) are more region and season-specific. For example, hail comprises greater than $25 \%$ of monthly indemnities for the NP during the summer months. During this time, the NW, NE, and SP also see increases in hail-related COL.

Heat (red) is most noticeable in the SW with fraction of monthly indemnities greater than $25 \%$ in many spring and summer months. During the summer months, heat is a consistent COL comprising at least 25\% of monthly indemnities especially in July, and sometimes greater than 50\%. More recently (2013 - 2016) heat has been an influential COL in the SW across all months, and the substantial proportion of monthly indemnities due to heat in November from 2013 to 2015 is striking. The NW also experiences high proportions of heat-related indemnities during the spring and summer months (June, July, August, and September).

In general, freeze (light blue) is most noticeable during the fall (October, November), winter (December, January, February), and early spring months (March, April). Except for the NP, MW, and SP regions, all other regions feature freeze as a large fraction of annual indemnities from 2001 to 2016. Freeze comprises more than a quarter of monthly indemnities most often for the NE and SE regions during winter and early spring months and the most often for NW and SW regions during the late fall and early winter months.

Failure in irrigation supply, or lack of water, (FIS; light green) has generally been reported as a COL for the SW between January and July, with an increasing fraction of monthly indemnity for May since 2008. Wind/excess wind (orange) frequently appears as an important COL for NP in January, February, and March. Other COL (gray) not listed in the top 10 nationwide list generally comprise greater than $25 \%$ of annual indemnities during the months of January and February for the SW, NP, MW, and NE regions. 
NW

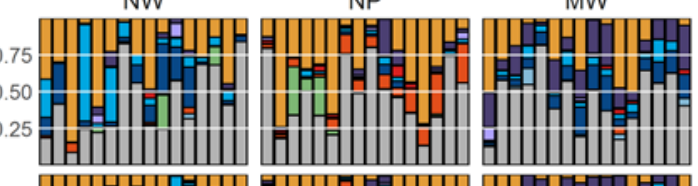

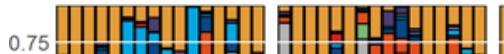
0.50 貝然期

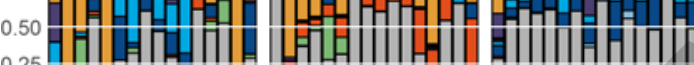

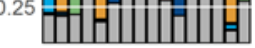

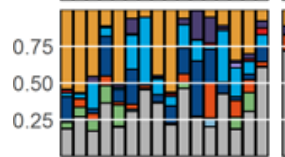
国川川川 0.50

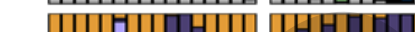
0.50
0.25

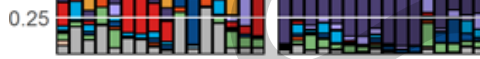

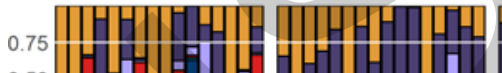

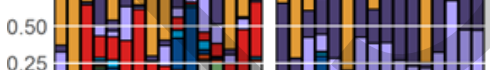

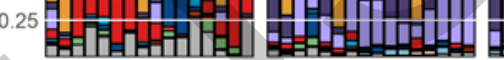

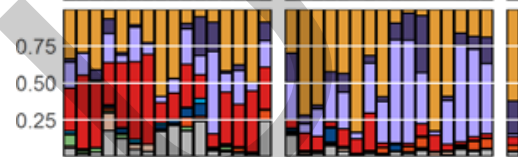

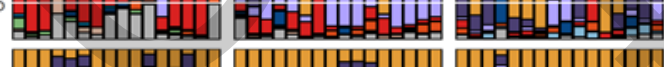

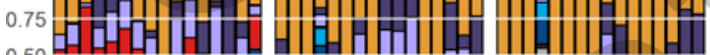

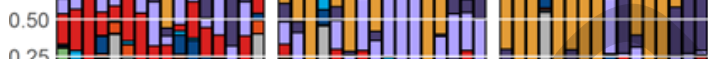

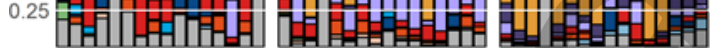

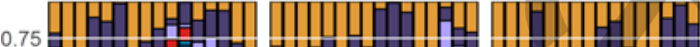

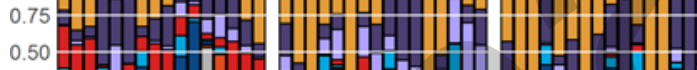

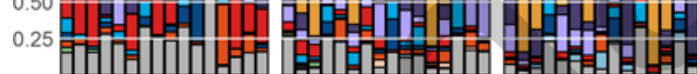

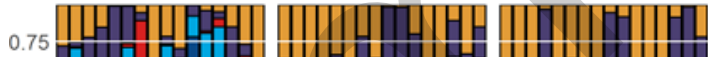

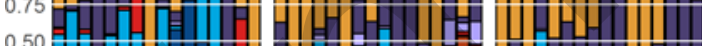

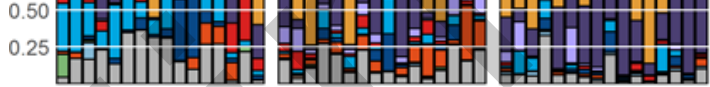
0.75 |||||||||||||||||||||| ||||||||||||

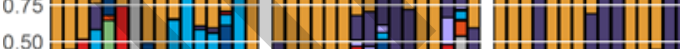

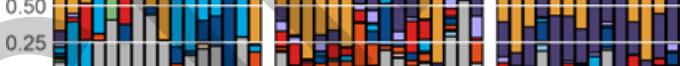

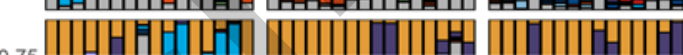

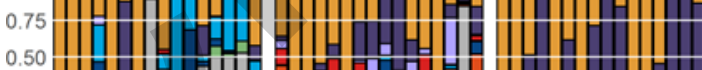

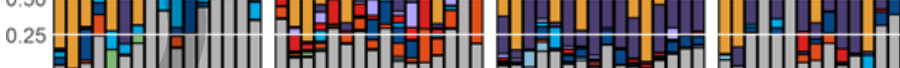
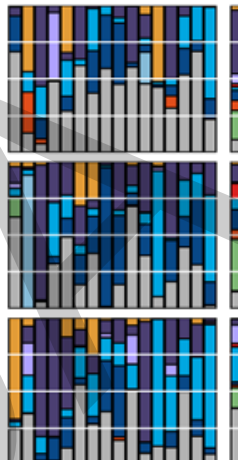

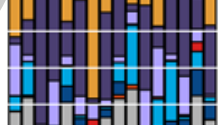

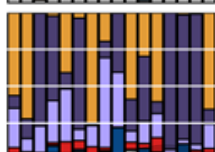

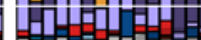

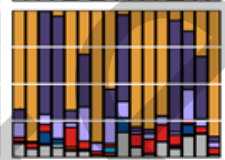

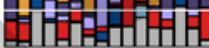

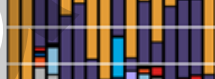

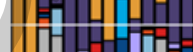

SW SP

SP $\quad$ SE

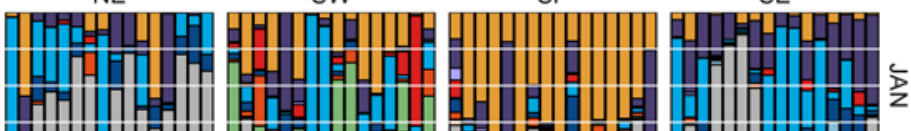

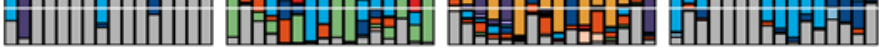
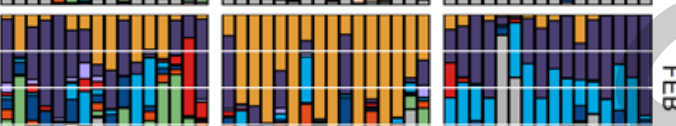

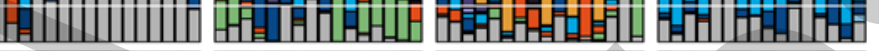

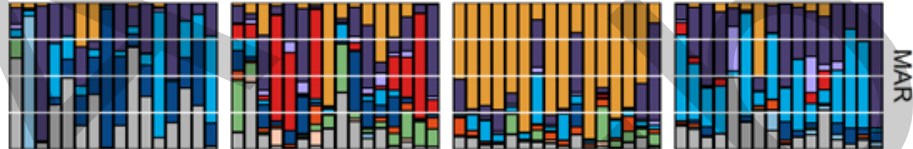

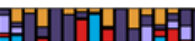

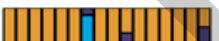

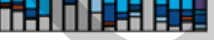

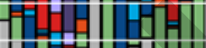

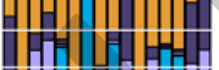
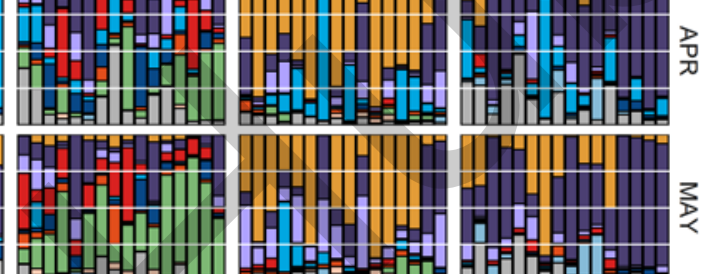

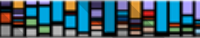
目计助助

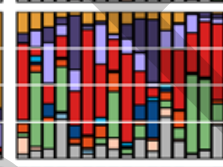

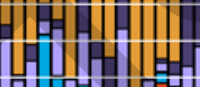

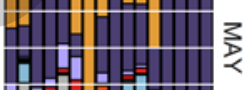

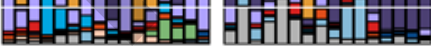

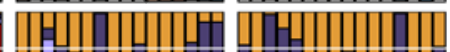

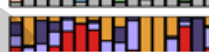

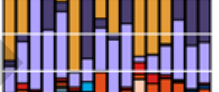

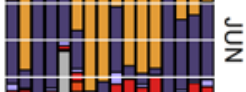

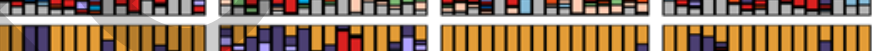

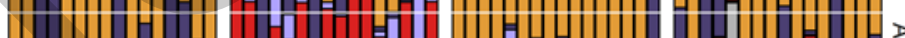

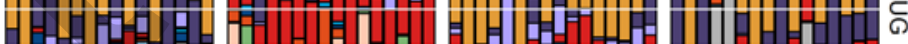

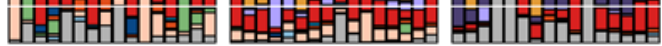

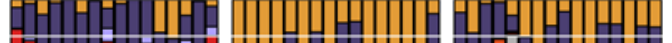

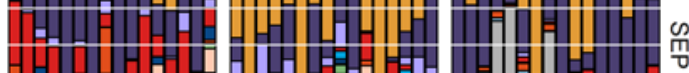

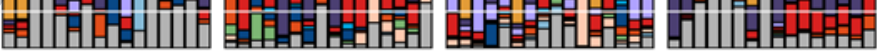

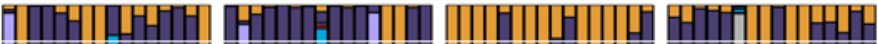
|

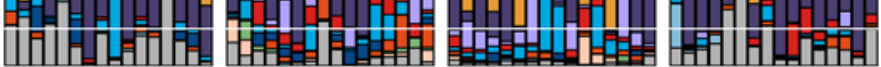

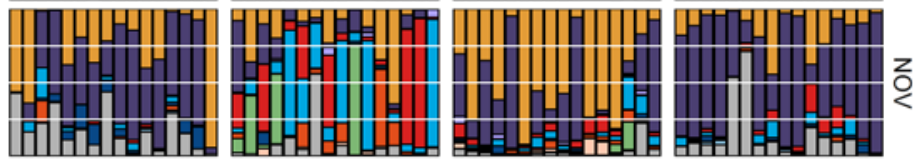

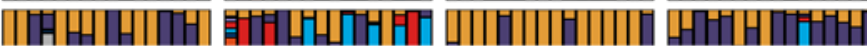

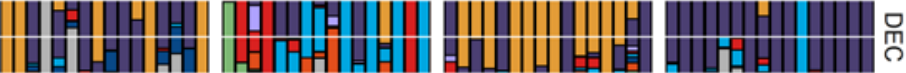

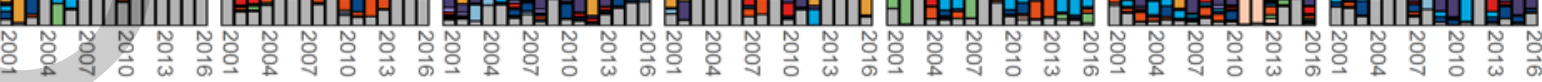

$\square$ Drought
$\square$ Excess Moisture/Precip/Rain
$\square$ Hail $\quad \begin{aligned} & \text { Heat } \\ & \begin{array}{l}\text { Freeze } \\ \text { Cold Wet Weather }\end{array}\end{aligned} \begin{aligned} & \text { Wind/Excess Wind } \\ & \begin{array}{l}\text { Failure Irrig Supply } \square \text { Fot Wind } \\ \text { Hother }\end{array}\end{aligned}$

Figure 10. Fraction of monthly indemnities (each month $=$ row) by region (columns) and by nationwide top COL (fill color) from 2001 to 2016. 


\section{$5 \quad$ Research applications}

\subsection{Questions}

Through our analysis and visualization of COL at various spatio-temporal scales (Objective 1), we have developed initial research questions to further assess any trends in COL and indemnities, as well as linkages with weather and climate. By doing so, we increase our understanding of how climate change may affect higher production risk areas leading to targeted adaptation and resilient communities (GAO, 2015). The following research questions (RQs) have been informed and shaped by Objective 1:

RQ1. Are there trends in indemnities related to COL over time?

RQ1a. How are these trends affected over differential spatial scales (e.g., national, regional, state, county)?

RQ1b. Are these trends in COL specific to particular commodities (i.e., crops)?

RQ2. To what extent are impacts from weather and climate expressed in indemnities and COL? RQ2a. Are indemnity and COL trends correlated with any weather and climate variables (e.g., temperature, precipitation, PDSI, SPIxx)?

RQ2b. What other hydro-climate variables (e.g., evapotranspiration, ET; soil moisture, etc.) or drought indices support trends in indemnities or changes in COL as a proportion of total indemnities?

\subsection{Methods}

Methods for RQ1. The Mann-Kendall test is used to test any significant, monotonic trends within individual time-series (e.g., annual rainfall, annual mean temperature, annual total indemnities).

Therefore, Mann-Kendall is most appropriate for annual aggregated data. Monthly indemnities would be more appropriately tested using the Seasonal Kendall test to account for the intra-annual (i.e. monthly or seasonal) patterns within the dataset (Helsel and Hersch, 2002).

The Mann-Kendall trend analysis will be used on subsets of the aggregated dataset grouping by individual COL, but also top COL by each state and region. We will also investigate normalization of indemnities to account for changes in programmatic structures and inflation (e.g., loss ratio, relative indemnities by COL). In addition, Mann-Kendall will be used for different commodities based on total liabilities and indemnities. These top commodities essentially represent those crops that have sustained the greatest losses in certain regions. The Seasonal Kendall test will be used on monthly data using the same procedure of subsetting data by COL and commodity as discussed.

Methods for RQ2. We use Kendall's test to examine the relationship between normalized indemnities and other weather/hydro-climate variables over different spatio-temporal scales and for varying COL. The Kendall rank correlation coefficient (i.e. Kendall's test) measures the association, or similarity, between two variables in a time series (Kendall, 1955; Hess et al., 2001; Abdi, 2007). Kendall's test is a nonparametric test based on ranked objects. The Kendall correlation coefficient is similar to other correlation tests such as Pearson's r, and rank correlation tests like Spearman's rho, in essentially identifying a statistical relationship between two sets of data (Kruskal, 1958). Kendall's test has been used in environmental applications, such as flood frequency and precipitation/sea surface temperatures (Schmocker-Fackel and Naef, 2010; Conway et al., 2015).

Monthly weather data including temperature (mean, minimum, maximum) and precipitation at multiple spatial scales will be accessed through the NOAA Regional Climate Centers (RCCs). Drought indices such as the Palmer Drought Severity Index (PDSI) and Standardized Precipitation Index (SPI) averaged across multiple months will also be used. 


\subsection{Limitations}

The proposed RQs and analyses only consider RMA indemnities and associated COL. As mentioned earlier, there is also disaster assistance available for producers and ranchers through the Farm Service Agency (FSA) for those crops not covered through the FCIC. Therefore, the trends in indemnities and reported COL over time may not accurately reflect all losses due to weather and climate perils. However, RMA-reported COL data will reflect a subset of those. We will use the USDA Climate Hubs network to consider FSA-related losses in our RQs and how that particular dataset aligns with the RMA-related indemnities. We also recognize numerous programmatic changes and policy provisions that may affect our RQ that may affect reporting of COL over time (e.g., creation of hot wind and FIS as individual COL categories).

\section{$6 \quad$ Outreach and extension}

As part of the mission of the USDA Climate Hubs, there is a large component of the RMA data analysis project intended to engage stakeholders including the general public, commodity groups, land grant universities, other Federal agencies, and other regional collaboratives. Here we describe a two-pronged approach for outreach and extension related to the RMA crop insurance data:

1. Development and evaluation of a web-based data visualization tool for RMA crop insurance COL data at multiple spatio-temporal scales

2. Engagement with researchers, practitioners, and stakeholders (e.g., regional research collaborations, RMA Regional Offices, commodity groups) using COL Climate Hub prepared fact sheets relevant to each Climate Hub region

These approaches to public outreach and extension of the RMA crop insurance data lead to the following outcomes: (1) better understand higher production risk areas in a changing climate and (2) create opportunities for co-production of research and knowledge between scientists and stakeholders (i.e., producers).

The Data Viewer (https://swclimatehub.info/rma/) is a web-based application developed and supported by the USDA Southwest Climate Hub and Agricultural Research Service Jornada Experimental Range (Figure 11). Aggregated monthly data from 1989 to 2016 (see Methods) with COL information are accessible and discoverable via the application at multiple spatial scales (i.e., nationwide, state, county) and temporal scales (i.e., annual, monthly). On-the-fly analysis is available based on user-defined parameters, such as selected commodities (e.g., wheat, corn, cotton) and/or COL (e.g., drought, heat, hail). Time-series of indemnities are available by COL (Figure 12) and by commodity (Figure 13), as well as aggregated totals by these variables, respectively. These values and time-series figures will change depending on the user selection of spatial scale and time period. Figures 13 and 14 are examples of “discoverable” Federal crop insurance data for the Nation from 1989 to 2016. 


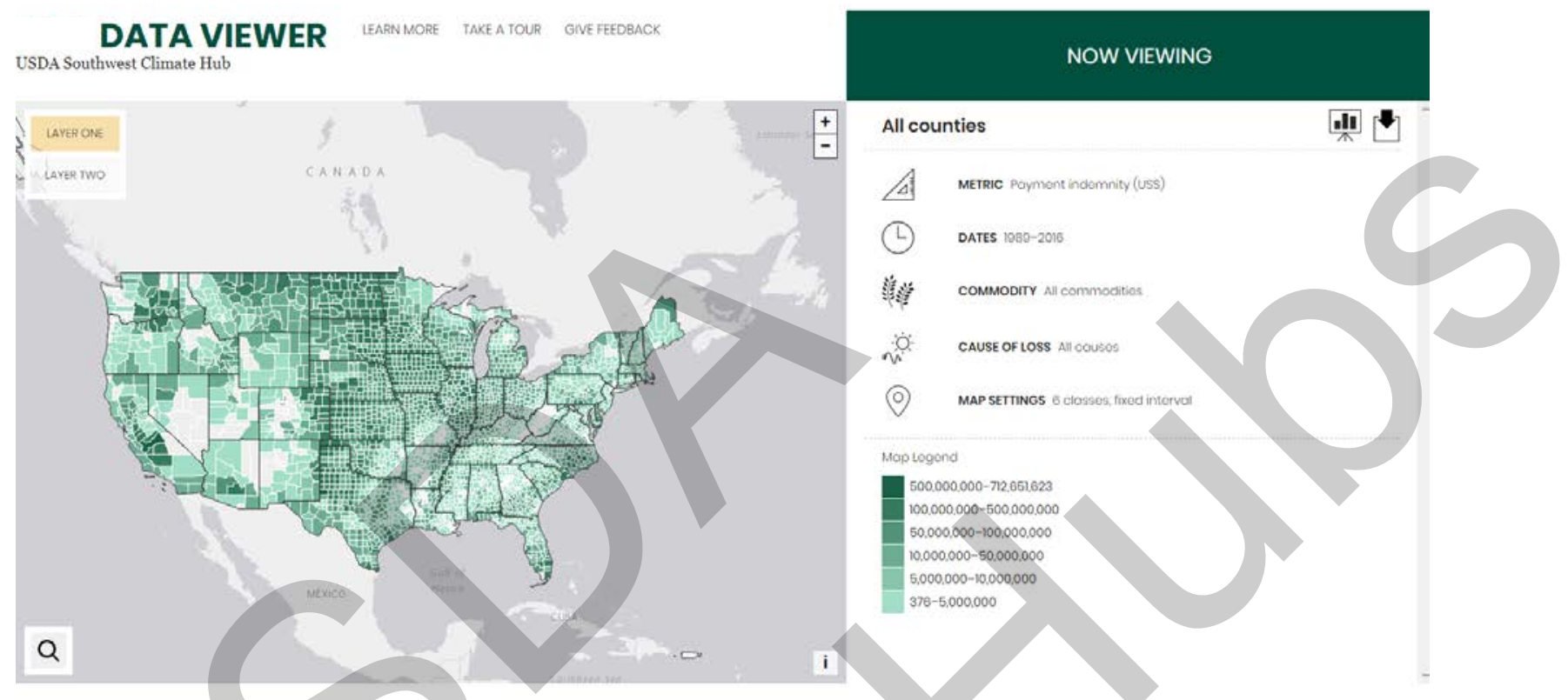

Figure 11. Screenshot of the Data Viewer. There are interactive panels for spatial scale selection (i.e., nationwide, state, county-level), temporal scale (i.e., annual, month), COL, and commodity. Users can also view time series of indemnities over time and by user-defined parameters.

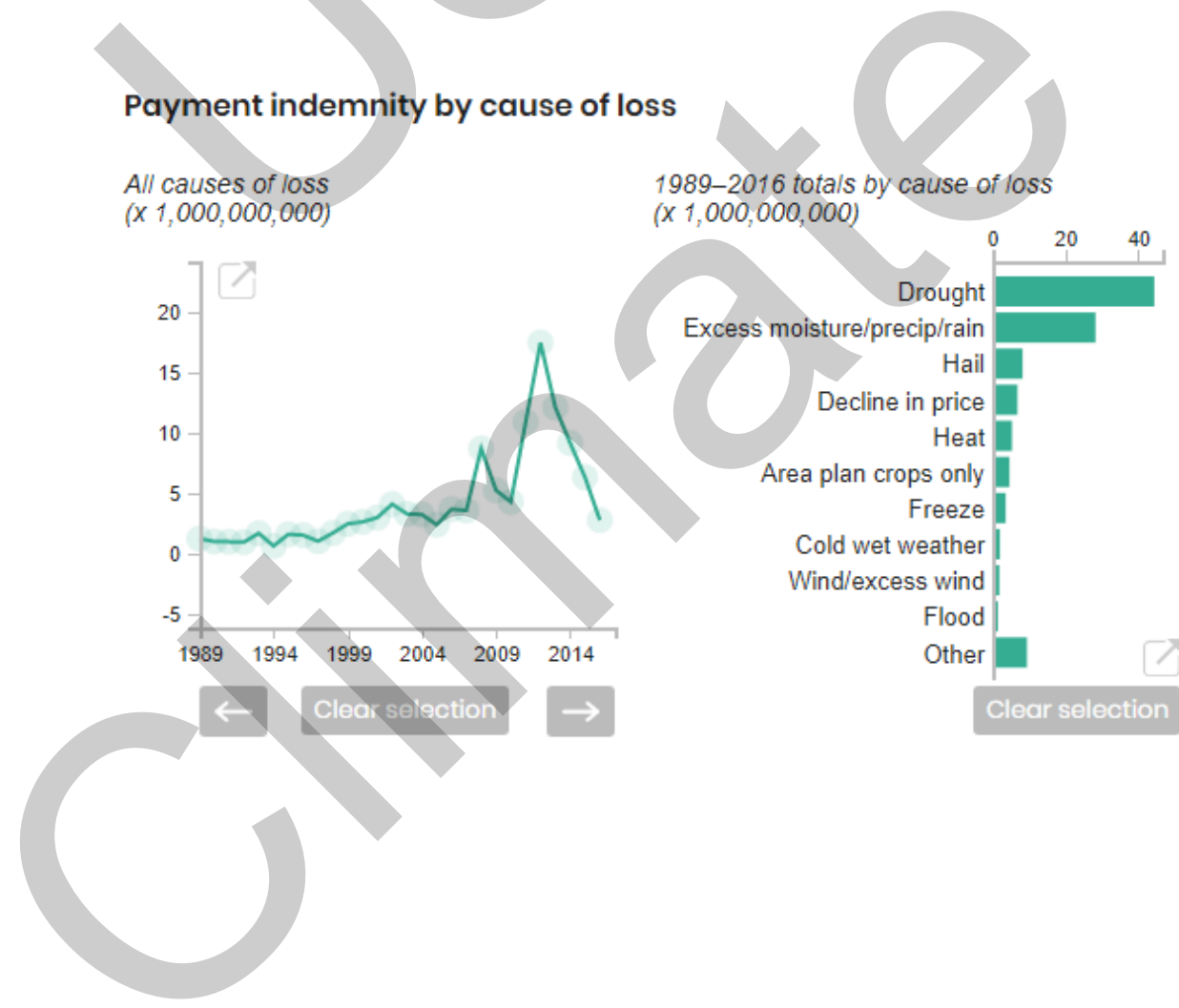

Figure 12. Screenshot of sample time-series analysis from the Data Viewer. Total annual indemnities are shown in the line graph (left) from 1989 to 2016 over the whole Nation. Indemnities aggregated by COL are shown as a bar plot (right) for the same period in billions of dollars. 


\section{Payment indemnity by commodity}

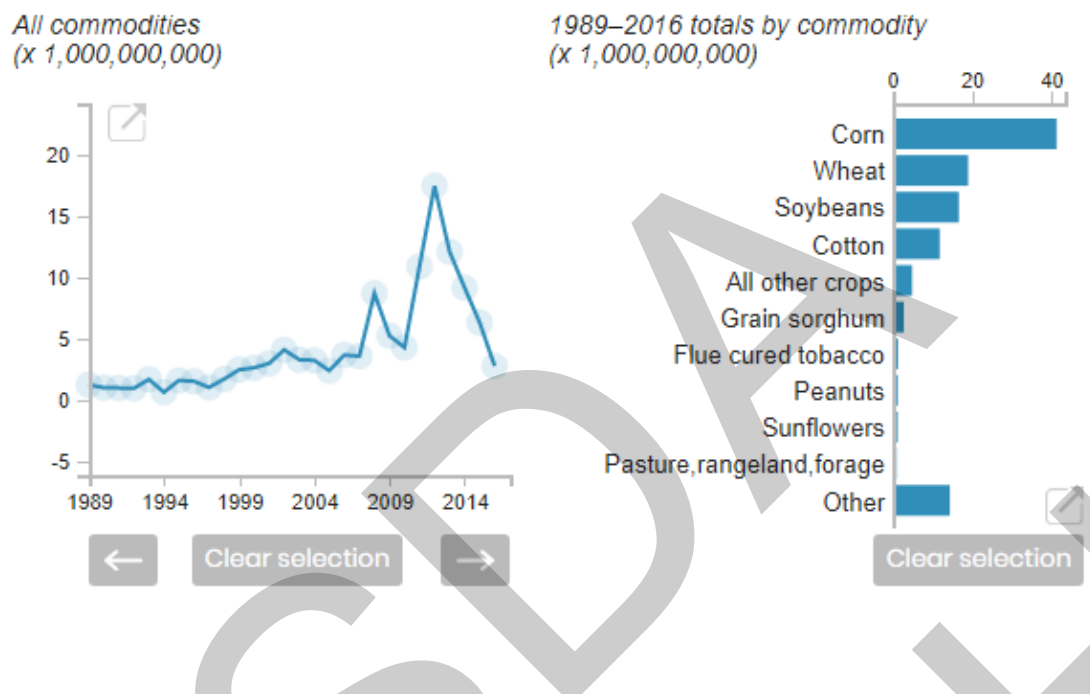

Figure 13. Screenshot of sample time-series analysis from the Data Viewer. Total annual indemnities are shown in the line graph (left) from 1989 to 2016 over the whole Nation. Indemnities aggregated by top commodities are shown as a bar plot (right) for the same period in billions of dollars.

A second component to the outreach and extension of the RMA project involves engagement with regional commodity groups and other collaboratives to help disseminate our COL analyses and share the Data Viewer. We will connect with RMA Public Affairs and regional offices ${ }^{4}$ (ROs) who have close connections with local producers, grower groups, researchers, and governmental agencies. Building off the spatio-temporal analysis presented here, feedback on Data Viewer use, and stakeholder engagement, we will produce summaries of COL that are analogous to the State Climate Summaries produced by the National Oceanic and Atmospheric Administration (NOAA) ${ }^{5}$. We will produce Climate Hub fact sheets that are easily distributed at producer meetings, conferences, and workshops. The structure of these summaries will provide a deeper understanding of potential production risks based on historic indemnity trends.

We have also engaged with researchers and other USDA agencies to increase the usability and usefulness of our analysis and Data Viewer. By working with our partners and stakeholders directly, we can produce analysis that is decision-relevant. Figure 14 is an example showing COL analysis for those counties located in the Ogallala Aquifer. The Ogallala Water Coordinated Agriculture Project (OWCAP) is a USDA National Institute of Food and Agriculture (NIFA) project focused on water decline and long-term agricultural sustainability in the High Plains, and includes producers, university researchers, Extension specialists, and ARS scientists. Through interactions with OWCAP, we have a better understanding of how these COL data may be useful to them. Other groups we have engaged with include the USDA Farm Service Agency and PRISM Climate Group.

\footnotetext{
${ }^{4}$ https://www.rma.usda.gov/aboutrma/fields/rsos.html

${ }^{5}$ https://statesummaries.ncics.org/
} 
Top county COL from 2001-2016

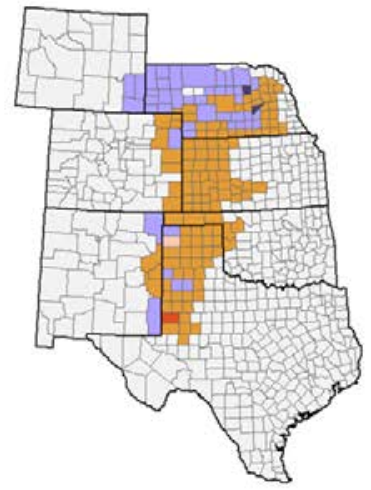

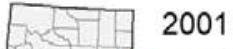

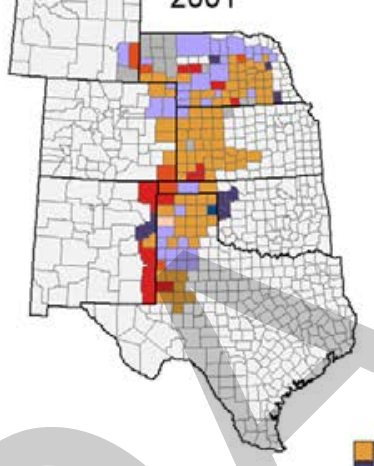

2011

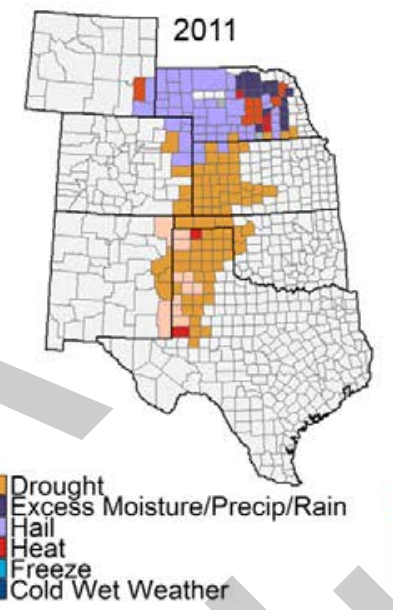

2012

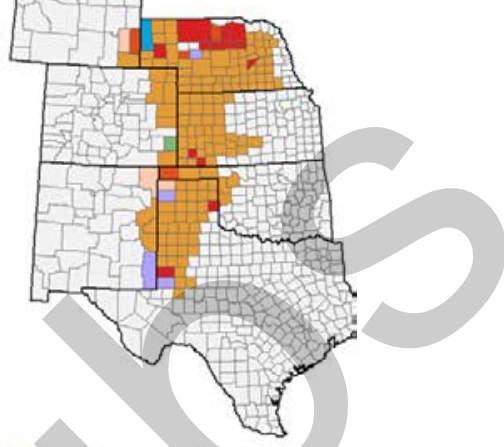

Figure 14. COL are highlighted for counties located in the Ogallala Aquifer. This image was developed for a regional research entity focusing on the Ogallala Aquifer and presented to the producers and researchers. Top county COL from 2001 to 2016 are shown with top COL for selected years - 2001, 2011, and 2012 showing the effects of the 2011-2012 drought in the High Plains area.
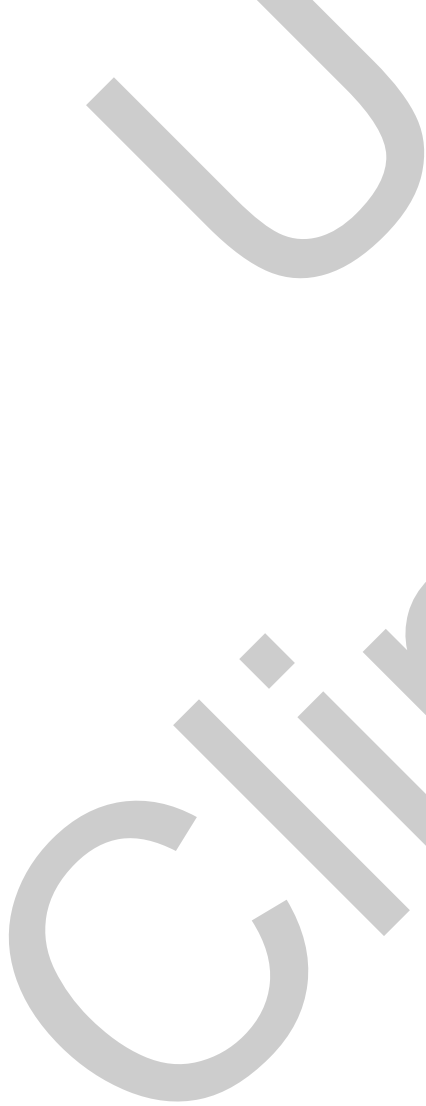


\section{References}

Botzen, W. J. W., Bergh, J. C. J. M. van den, \& Bouwer, L. M. (2010). Climate change and increased risk for the insurance sector: a global perspective and an assessment for the Netherlands. Natural Hazards, 52(3), 577-598. https://doi.org/10.1007/s11069-009-9404-1

Bouwer, L. M. (2010). Have Disaster Losses Increased Due to Anthropogenic Climate Change? Bulletin of the American Meteorological Society, 92(1), 39-46. https://doi.org/10.1175/2010BAMS3092.1

Elias, E., C. Steele, K. Havstad, K. Steenwerth, Chambers, J., H. Deswood, A.Kerr, A. Rango, M. Schwartz , P. Stine, R. Steele, 2015: Southwest Regional Climate Hub and California Subsidiary Hub Assessment of Climate Change Vulnerability and Adaptation and Mitigation Strategies, T. Anderson, Ed., United States Department of Agriculture, 76 pp.

Foley, J. A., Ramankutty, N., Brauman, K. A., Cassidy, E. S., Gerber, J. S., Johnston, M., ... Zaks, D. P. M. (2011). Solutions for a cultivated planet. Nature, 478(7369), 337-342. https://doi.org/10.1038/nature10452

Godfray, H. C. J., Beddington, J. R., Crute, I. R., Haddad, L., Lawrence, D., Muir, J. F., ... Toulmin, C. (2010). Food Security: The Challenge of Feeding 9 Billion People. Science, 327(5967), 812818. https://doi.org/10.1126/science.1185383

Government Accountability Office. (2014). Climate change: Better management of exposure to potential future losses is needed for federal food and crop insurance (GAO-15-28). Washington, DC.

Government Accountability Office. (2015). Crop insurance: In areas with higher crop production risks, costs are greater, and premiums may not cover expected losses (GAO-15-215). Washington, DC.

Government Accountability Office. (2017). Climate change: Information on potential economic effects could help guide federal efforts to reduce fiscal exposure (GAO-17-720). Washington, DC.

Hatfield, J. L., K. J. Boote, B. A. Kimball, L. H. Ziska, R. C. Izaurralde, D. Ort, A. M. Thomson, and D. Wolfe, 2011: Climate impacts on agriculture: Implications for crop production. Agronomy Journal, 103, 351-370, doi:10.2134/agronj2010.0303.

Mcleman, R., \& Smit, B. (2006). Vulnerability to climate change hazards and risks: crop and flood insurance. Canadian Geographer / Le Géographe Canadien, 50(2), 217-226. https://doi.org/10.1111/j.0008-3658.2006.00136.x

Shields, D. (2015). Federal Crop Insurance: Background (No. R40532). Congressional Research Service.

Walthall, C. et al., 2012: Climate Change and Agriculture in the United States: Effects and Adaptation. USDA Technical Bulletin 1935. 186 pp., U.S. Department of Agriculture and the U.S. Global Change Research Program, Unpublished. URL | Detail 